\title{
Using mathematical models to understand the effect of nanoscale roughness on protein adsorption for improving medical devices
}

This article was published in the following Dove Press journal:

International Journal of Nanomedicine

13 September 2013

Number of times this article has been viewed

\author{
Batur Ercan' \\ Dongwoo Khang ${ }^{2}$ \\ Joseph Carpenter ${ }^{3}$ \\ Thomas J Webster \\ 'Department of Chemical Engineering, \\ Northeastern University, Boston, MA, \\ USA; ${ }^{2}$ School of Materials Science \\ and Engineering and Center for PRC \\ and RIGET, Gyeongsang National \\ University, Jinju, South Korea; ${ }^{3}$ School \\ of Medicine, Stanford University, \\ Stanford, CA, USA
}

\begin{abstract}
Surface roughness and energy significantly influence protein adsorption on to biomaterials, which, in turn, controls select cellular adhesion to determine the success and longevity of an implant. To understand these relationships at a fundamental level, a model was originally proposed by Khang et al to correlate nanoscale surface properties (specifically, nanoscale roughness and energy) to protein adsorption, which explained the greater cellular responses on nanostructured surfaces commonly reported in the literature today. To test this model for different surfaces from what was previously used to develop that model, in this study we synthesized highly ordered poly(lactic-co-glycolic acid) surfaces of identical chemistry but altered nanoscale surface roughness and energy using poly(dimethylsiloxane) molds of polystyrene beads. Fibronectin and collagen type IV adsorption studies showed a linear adsorption behavior as the surface nanoroughness increased. This supported the general trends observed by Khang et al. However, when fitting such data to the mathematical model established by Khang et al, a strong correlation did not result. Thus, this study demonstrated that the equation proposed by Khang et al to predict protein adsorption should be modified to accommodate for additional nanoscale surface property contributions (ie, surface charge) to make the model more accurate. In summary, results from this study provided an important step in developing future mathematical models that can correlate surface properties (such as nanoscale roughness and surface energy) to initial protein adsorption events important to promote select cellular adhesion. These criteria are critical for the fundamental understanding of the now welldocumented increased tissue growth on nanoscale materials.
\end{abstract}

Keywords: nanophase topography, surface energy, collagen type IV, fibronectin, adsorption, modeling, nanoscale roughness, proteins

\section{Introduction}

Upon the insertion of an implant inside the body, proteins adsorb on to the surface within the first couple of seconds, and these adsorbed proteins mediate cellular adhesion on to the implant surfaces. ${ }^{1,2}$ One of the most influential parameters controlling the adsorption of proteins centers on surface properties (such as roughness and energy) of an implant. By altering implant surface properties, it is possible to guide select protein adsorption, as well as control the quantity and conformation of the adsorbed proteins, allowing researchers to guide select cell adhesion on to the implant surfaces, potentially improving the success of the implant. ${ }^{3}$ Some of the important parameters that control protein adsorption on to biomaterial surfaces are surface chemistry, roughness, wettability, and charge..$^{4-7}$

Along this line, one of the most promising approaches to altering surface properties of biomaterials is decreasing the material surface feature size into the nanophase regime.
Correspondence: Thomas J Webster Department of Chemical Engineering, Northeastern University, 360 Huntington Avenue Boston, MA 02115-5000, USA

Tel +l 6173736585

Email th.webster@neu.edu 
When using a nanophase material, where at least one surface feature size is less than $100 \mathrm{~nm}$, implant surface properties will change (ie, surface area, energy, topography, and charge). ${ }^{8}$ In fact, researchers have been proposing the use of nanophase materials for a variety of tissue engineering applications, including for bone, cartilage, vascular, neural applications, and the bladder. ${ }^{9}$ Cumulatively, there is plenty of evidence showing enhanced cellular functions on nanophase materials compared with their nanosmooth counterparts. ${ }^{7}$ Specifically in orthopedics, some of the chemistries that demonstrate higher cellular adhesion and long-term cellular functions upon the creation of a nanophase topography are $\mathrm{TiO}_{2}$, $\mathrm{Al}_{2} \mathrm{O}_{3}$, hydroxyapatite, poly(lactic-co-glycolic acid) (PLGA), carbon nanotubes, and carbon nanofibers. ${ }^{10,11}$ Although the list can be expanded with various other surface chemistries and tissue types, the major reason for this enhancement in cellular functions has been correlated with the interaction of the adherent cells with the initially adsorbed proteins on to the biomaterial surface. ${ }^{12,13}$

As it is crucial to understand the effect of surface properties on protein adsorption experimentally, ${ }^{14,15}$ a simplified equation elucidating the influence of unique surface parameters (ie, chemistry, charge, micron/nanophase topography, wettability, and crystallinity) on protein adsorption was proposed by Khang et al. ${ }^{16}$ However, the Khang et al equation has not been tested using other materials to date. Toward this goal, in this research we utilized that simplified Khang et al equation to model the influence of PLGA surface nanoroughness and energy on the protein adsorption events important for controlling select cell adhesion. ${ }^{16}$ To investigate the efficacy of the proposed protein adsorption model, we synthesized PLGA surfaces with varying nanoscale topographies, while keeping the surface chemistry the same, and assessed collagen type IV and fibronectin adsorption on to these surfaces. The results provided significant clues into how one can develop improved mathematical models to correlate nanoscale surface roughness to initial protein adsorption events.

\section{Materials and methods PLGA film synthesis}

The details of the process used to create PLGA nanoscale surface topographies are explained in a previous publication. ${ }^{14}$ Briefly, $18 \mathrm{~mm}$ borosilicate glass coverslips (Thermo Fisher Scientific, Waltham, MA, USA) were cleaned by acetone and $70 \%$ ethanol (soaked in each liquid for 10 minutes and then sonicated for another 10 minutes) followed by rinsing with $\mathrm{diH}_{2} \mathrm{O}$. A total of $300 \mu \mathrm{L}$ of a $10 \mathrm{wt} \%$ solution of polystyrene (PS) beads $190 \mathrm{~nm}, 300 \mathrm{~nm}$, or $400 \mathrm{~nm}$ in diameter (Bangs Laboratories, Fishers, IN, USA) were separately dispersed on to the coverslips and allowed to evaporate in ambient air. PS beads were secured to a $1 \mathrm{~cm}$ (height) $\times 18 \mathrm{~mm}$ diameter glass rod. Poly(dimethylsiloxane) (PDMS, Sylgard ${ }^{\circledR} 184$ silicone elastomer, Dow Corning Corporation, Midland, MI, USA) was mixed at 1:10 vol\% (curing agent:base) and poured on to the glass rod/PS construct, before the bubbles were removed under vacuum (25 in $\mathrm{Hg}$, for 20 minutes), and was cured at room temperature for 48 hours. PDMS molds were peeled and rinsed with chloroform to remove any residual PS beads from the PDMS surfaces. PLGA (50:50 wt:wt \%, molecular weight 12-16× $10^{3} \mathrm{~g}$, Polysciences, Inc., Warrington, PA, USA) was dissolved by sonicating at a ratio of $0.5 \mathrm{~g}$ PLGA to $8 \mathrm{~mL}$ chloroform and then poured on to the PDMS molds, allowing for evaporation of the chloroform to occur for 48 hours at room temperature. The PLGA films were then peeled and cut into $12 \mathrm{~mm}$ diameter disks. The control surfaces were created by dissolving PLGA in chloroform, before $300 \mu \mathrm{L}$ of the solution was cast on to $12 \mathrm{~mm}$ coverslips, allowing chloroform to evaporate for 4 hours at room temperature.

\section{Sample characterization}

Atomic force microscopy (AFM) topographies of nano/ submicron featured PLGA films were obtained in ambient air using a Digital Instruments DI-310 AFM (Santa Barbara, CA, USA). Tapping mode was used at $320 \mathrm{kHz}$ with a scan rate of $0.5 \mathrm{~Hz}$ and 256 lines/scan. A scan area of $5 \mu \mathrm{m} \times 5 \mu \mathrm{m}$ or $2 \mu \mathrm{m} \times 2 \mu \mathrm{m}$ was investigated. The AFM tip had a radius of curvature less than $10 \mathrm{~nm}$, a cone angle of $30^{\circ}$, and a cantilever force constant of roughly $40 \mathrm{~N} / \mathrm{m}$ coated on the back with aluminum (DP15/Al BS, MikroMasch $^{\circledR}$, NanoWorld AG, Neuchâtel, Switzerland). Images were analyzed using Nanoscope 4.42 software (Digital Instruments). As was done by Khang et al, ${ }^{16}$ the obtained root mean squared (RMS) roughness values were multiplied by an area factor $\mathrm{S}_{\mathrm{N}}\left(\mathrm{S}_{\mathrm{N}}=\mathrm{S}_{\text {unit }} / \mathrm{S}_{\text {measured }} ; \mathrm{S}_{\text {unit }}=2 \mathrm{D}\right.$ surface area, and $\mathrm{S}_{\text {measured }}=$ measured greater surface area due to increased roughness) to compensate for the incremental changes in surface area. In addition, and similar to Khang et al, ${ }^{16}$ in this research $\mathrm{RMS}_{\text {effective }}$ was used as a new roughness factor $\left(\mathrm{RMS}_{\text {effective }}=\mathrm{RMS}_{\text {measured }} \times \mathrm{S}_{\mathrm{N}}\right)$.

A drop-shaped analysis system (DSA-10, Krüss GmbH, Hamburg, Germany) was used to complete the contact angle measurements. Static contact angles were obtained immediately after the deposition of $3 \mu \mathrm{L} \mathrm{diH_{2 }} \mathrm{O}$ on to the sample under ambient conditions. Surface energy was calculated using $\mathrm{E}_{\mathrm{s}}=\mathrm{E}_{\mathrm{lv}} \times \cos \theta$, where $\mathrm{E}_{\mathrm{s}}$ is the surface energy of PLGA, 
$\theta$ is the water contact angle, and $\mathrm{E}_{\mathrm{lv}}$ (surface energy between air and water) is $72.8 \mathrm{~mJ} / \mathrm{m}^{2}$ at $20^{\circ} \mathrm{C}$ for pure water.

\section{Protein adsorption}

Samples were rinsed with phosphate-buffered saline and incubated for 1 hour with 1\% bovine fibronectin (SigmaAldrich, St Louis, MO, USA) or 1\% collagen type IV (Abcam plc, Cambridge, UK). Following this, sample surfaces were blocked by incubating in $1 \%$ bovine serum albumin (Sigma-Aldrich) for 1 hour, and then incubated with a 3:1,000 solution of rabbit antibovine fibronectin polyclonal antibody (Chemicon, EMD Millipore Corporation, Billerica, MA, USA) or rabbit antibovine collagen type IV polyclonal antibody (Abcam plc) in $1 \%$ bovine serum albumin. After washing with $0.05 \%$ Tween 20 (Sigma-Aldrich) in phosphatebuffered saline, a horseradish peroxidase conjugated secondary goat antirabbit $\operatorname{IgG}(\mathrm{H}+\mathrm{L})$ (Bio-Rad Laboratories, Hercules, CA, USA) was added. Samples were tested for the horseradish peroxidase activity using an ABST kit (Vector Laboratories, Inc, Burlingame, CA, USA), according to the manufacturer's instructions. Light absorbance measurements at $405 \mathrm{~nm}$ were completed using a spectrophotometer and associated software (SoftMax Pro 5, Molecular Devices LLC, Sunnyvale, CA, USA). The absorbance readings were normalized with the surface area of the samples obtained from AFM measurements and with the control sample without any imprinted topography.

\section{Statistics}

All experiments were run in triplicate and repeated at least three separate times. Results were analyzed for statistical significance using a Student's $t$-test, where $P<0.05$ was defined to assess the statistical significance. Linear regression analysis and $10 \%$ confidence intervals (shown with the pink shaded area on the graphs [Figure 3]) were determined using JMP ${ }^{\circledR}$ software (SAS Institute Inc, Cary, NC, USA) for statistical analysis.

\section{Results \\ Experimental data}

AFM images (Figure 1) showed that the spherical surface topography was effectively transferred to the PLGA surfaces. Interestingly, the line scan analysis (not shown) indicated that the lateral and vertical feature sizes were not similar. Although the lateral feature sizes were approximately $( \pm 5 \%)$ similar to the original PS bead size, the vertical feature sizes (shown in Table 1) did not follow a similar pattern. PLGA surfaces created using $300 \mathrm{~nm}$ beads had higher vertical dimension than the ones with $400 \mathrm{~nm}$ dimension. In fact, the surfaces created using $350 \mathrm{~nm}$ PS beads had vertical feature sizes $\sim 17 \times$ larger than the ones created using $190 \mathrm{~nm}$ beads. Furthermore, the surface free energy studies (Figure 2) showed that as the surface feature size increased, so did the hydrophobicity of the samples, with the exception of samples with the $18.9 \mathrm{~nm}$ feature size. Hydrophilicity was significantly different $(P<0.05)$ when comparing any two substrates of interest in this study. In this study, surface chemistry analysis was not conducted, because it was shown in a previous publication that PLGA casting using PDMS molds had identical chemistries. ${ }^{15}$

The results in this study showed that fibronectin and collagen type IV exhibited similar adsorption affinities on PLGA surfaces (Figure 2). In fact, protein adsorption followed a $\gamma$ distribution with regard to the surface feature size, with a maximum at $18.9 \mathrm{~nm}$ feature size. Surfaces with $4.9 \mathrm{~nm}$ and $18.9 \mathrm{~nm}$ features showed enhanced fibronectin and collagen type IV adsorption $(P<0.05)$ compared with the control surfaces.

\section{Mathematical model}

As mentioned, in this study a previously derived protein adsorption model was used to understand the adsorption of collagen type IV and fibronectin on to PLGA surfaces with varying topographies and surface energy. ${ }^{16}$ Firstly, RMS $_{\text {effective }}$
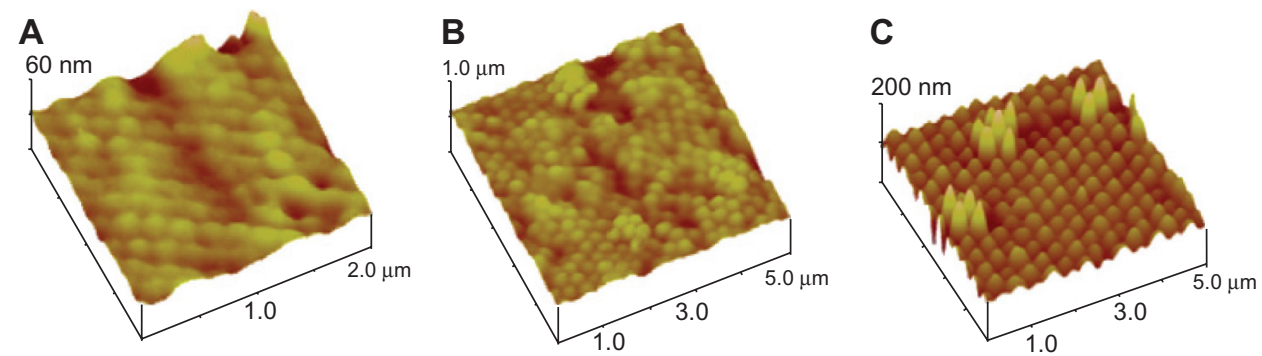

Figure I Atomic force microscopy images of the poly(lactic-co-glycolic acid) surfaces synthesized using a template covered with polystyrene nanobeads. The dimensions of the polystyrene nanobeads were: (A) $190 \mathrm{~nm}$, (B) $300 \mathrm{~nm}$, and (C) $400 \mathrm{~nm}$. Spherical surface features were effectively transferred to the poly(lactic-co-glycolic acid) surfaces, and ordered surface features were observed. 
Table I Summary of polystyrene bead size and corresponding vertical surface feature dimension (obtained by atomic force microscopy height profiles) and effective root mean squared roughness $\left(\mathrm{RMS}_{\text {eff }}\right)$ values

\begin{tabular}{lll}
\hline Bead size $(\mathbf{n m})$ & Vertical dimension $(\mathbf{n m})$ & RMS $_{\text {eff }}(\mathbf{n m})$ \\
\hline Control & Control & 0 \\
190 & $4.9 \pm 0.4$ & $2.69 \pm 0.0$ \\
300 & $86.3 \pm 2.9$ & $28.02 \pm 1.0$ \\
400 & $18.9 \pm 3.5$ & $13.32 \pm 1.1$ \\
\hline
\end{tabular}

Notes: Although the lateral surface feature size was similar to the bead size (data not shown), the vertical feature dimensions were not directly proportional to the bead size. The $300 \mathrm{~nm}$ beads showed a larger vertical dimension and RMS eff on poly(lactic-co-glycolic acid) replicas compared with the $400 \mathrm{~nm}$ beads. Values are mean \pm standard error of the mean.

and surface energy of the PLGA samples were correlated using a linear equation, as shown in Figure 3A. The relationship between $\mathrm{RMS}_{\text {effective }}\left(\mathrm{RMS}_{\text {eff }}\right)$ and surface energy $\left(\mathrm{E}_{\mathrm{s}}\right)$ can be formatted as shown in Equation 1: ${ }^{16}$

$$
\mathrm{E}_{\mathrm{s}}\left(\mathrm{RMS}_{\text {eff }}\right)=\rho \times \mathrm{RMS}_{\text {eff }}+\mathrm{E}_{\mathrm{o}, \mathrm{s}}
$$

In this formula, $\mathrm{E}_{\mathrm{o}, \mathrm{s}}$ (ground surface energy) is a material property determined purely by chemical interactions between the surface and the interacting liquid for negligible surface roughness (not a function of nanoscale topography), and $\rho$ is a coupling constant, which determines the extent of the influence of nanoscale topography on the surface energy of material. Line fitting the present experimental results gave $\mathrm{E}_{\mathrm{S}}=-0.47 \times \mathrm{RMS}_{\text {eff }}+8.92\left(R^{2}=0.46\right)$, where $\rho=-0.47$ and $\mathrm{E}_{\mathrm{o}, \mathrm{s}}=8.92$.

As previously stated, surface nanophase topography and surface energy both affect protein adsorption on to biomaterial surfaces. If we ignore the other parameters and consider only these two parameters, the simplified formula for adsorption of a protein is: ${ }^{16}$

$$
\mathrm{F}_{\text {adsorption }}\left(\mathrm{RMS}_{\text {eff }}, \mathrm{E}_{\mathrm{s}}\right)=\alpha \times \mathrm{RMS}_{\text {eff }}+\beta \times \mathrm{E}_{\mathrm{s}}
$$

where $\mathrm{F}_{\text {adsorption }}$ is protein adsorption (normalized with AFM surface area), $E_{s}$ is surface energy of the material, and $\alpha$ and $\beta$ are coupling constants correlating protein adsorption with surface nanophase roughness $(\alpha)$ and surface energy $(\beta)$. When Equations 1 and 2 are coupled, it is possible to define protein adsorption as a function of only $\mathrm{RMS}_{\text {eff }}$, as shown in Equation 3: ${ }^{16}$

$$
\mathrm{F}_{\text {adsorption }}\left(\mathrm{RMS}_{\text {eff }}\right)=\mathrm{A} \times \mathrm{RMS}_{\text {eff }}+\beta \times \mathrm{E}_{\mathrm{o}, \mathrm{s}}
$$

Here, $A$ and $\beta$ are coupling constants for nanophase roughness and ground surface energy, respectively, where $A=\alpha+\beta \times \rho$. Coupling constant $A$ indicates the contribution of

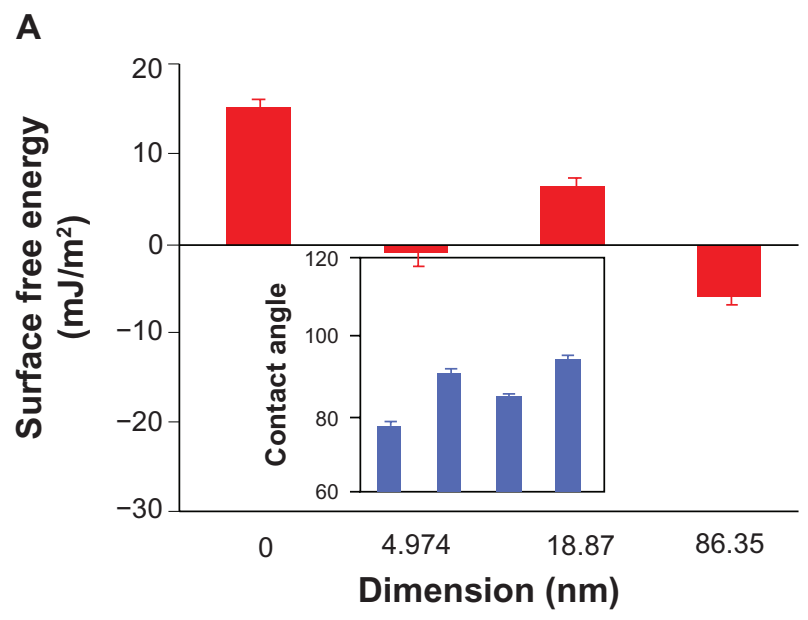

B

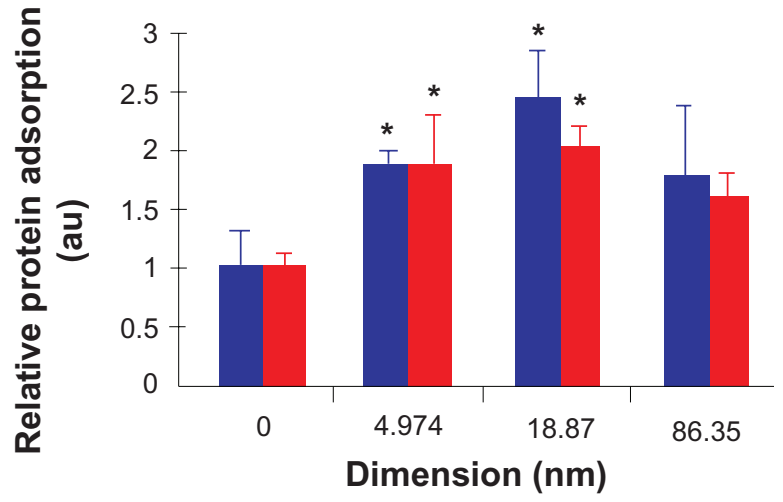

Figure 2 The effect of the change in the poly(lactic-co-glycolic acid) surface feature size on (A) surface energy (red) and water contact angles (blue), and (B) relative collagen type IV (blue or left) and fibronectin (red or right) adsorption. Surface energy and water contact angle results are significantly $(P<0.05)$ different between all data points. Values are mean \pm standard error of the mean. $* P<0.05$ compared with control surfaces.

nanophase surface roughness, and $\beta$ indicates the contribution of ground surface energy on the protein adsorption on to a biomaterial surface. When the protein adsorption results in this study are fit linearly with $\mathrm{RMS}_{\text {eff }}$ (Figure $3 \mathrm{~B}$ and C), the derived equation for collagen type IV adsorption is Coll adsorp $=0.02 \times$ $\mathrm{RMS}_{\text {eff }}+1.52\left(R^{2}=0.22\right)$, and for fibronectin adsorption is $\mathrm{FN}_{\text {adsorp }}=0.01 \times \mathrm{RMS}_{\text {eff }}+1.47\left(R^{2}=0.13\right)$.

On the other hand, when Equations 1 and 3 are combined, it is possible to write the protein adsorption as a function of only surface energy, as shown in Equation 4:16

$$
\mathrm{F}_{\text {adsorption }}=(\kappa+\beta) \times \mathrm{E}_{\mathrm{s}}-\kappa \times \mathrm{E}_{\mathrm{o}, \mathrm{s}}
$$

where $\kappa=\alpha / \rho$ is a coupling constant to correlate surface energy with protein adsorption. When the protein adsorption data are correlated with surface energy (Figure 3D and E), the obtained linear regression for the collagen type IV adsorption 
A

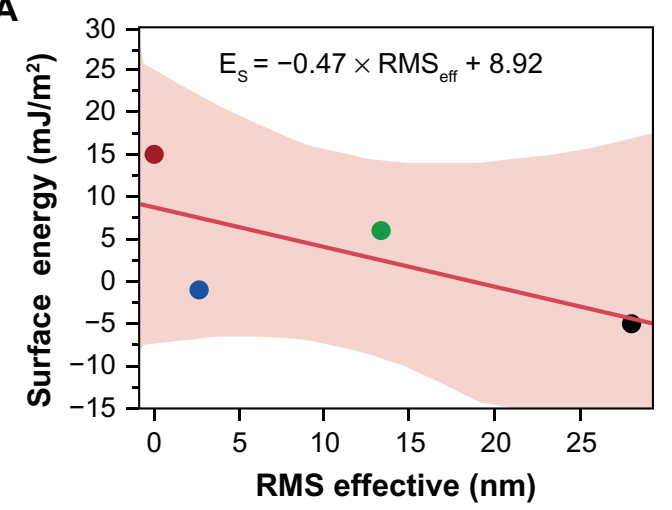

B

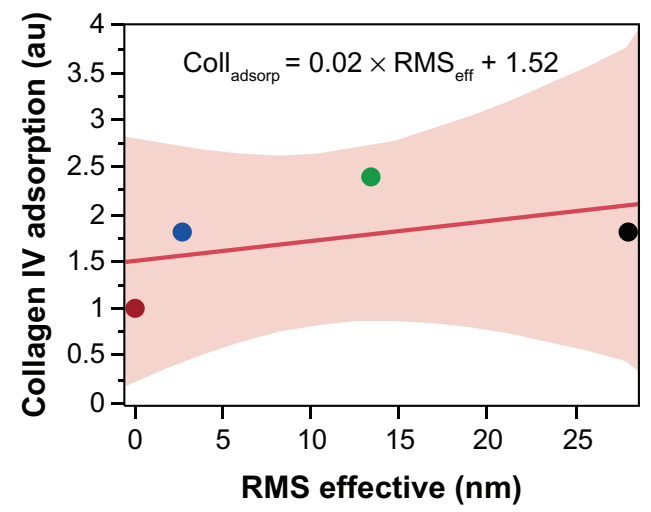

D

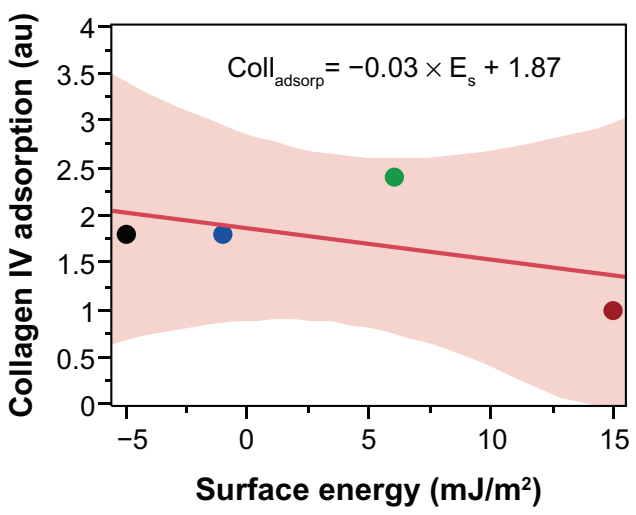

C

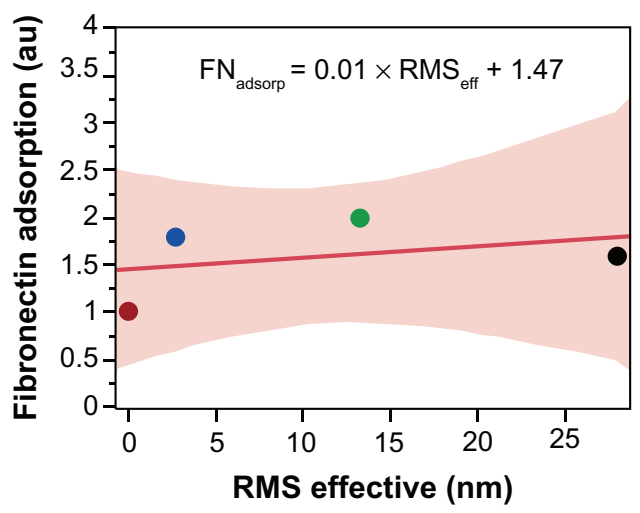

E

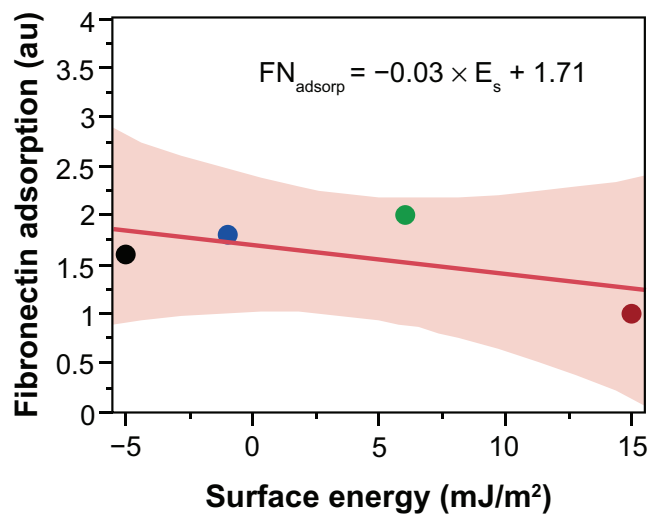

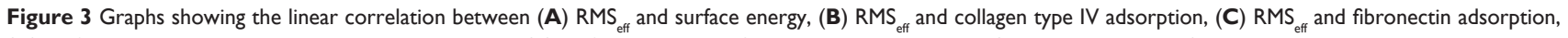
(D) surface energy and collagen type IV adsorption, and (E) surface energy and fibronectin adsorption. Poly(lactic-co-glycolic acid) sample synthesized using a polystyrene template bead size of $190 \mathrm{~nm}$ is blue, $300 \mathrm{~nm}$ is black, $400 \mathrm{~nm}$ is green, and red is the control sample. Equation I $\left(\mathrm{E}_{\mathrm{s}}\left[R M S_{\text {eff }}\right]=\rho \times \mathrm{RMS}_{\text {eff }}+\mathrm{E}_{\mathrm{o}, \mathrm{s}}\right)$ was used to model RMS $\mathrm{eff}$ and surface energy interactions in Figure $3 \mathrm{~A}$, Equation $3\left(\mathrm{~F}_{\text {adsorption }}\left[\mathrm{RMS}_{\text {eff }}\right]=\mathrm{A} \times \mathrm{RMS}_{\text {eff }}+\beta \times \mathrm{E}_{0, \mathrm{~s}}\right)$ was used to model surface nanoroughness and protein adsorption in Figure $3 B$ and $C$, and Equation $4\left(F_{\text {sdsortion }}\left[E_{s}\right]=[\kappa+\beta] \times E_{s}-\kappa \times E_{o s}\right)$ was used to model surface energy and protein adsorption in Figure 3D and $E$. In these equations $\rho, \alpha$, $\beta, A$, and $\kappa$ are coupling constants, where $A=\alpha+\beta \times \rho$ and $\kappa=\alpha / \rho$.

Abbreviations: Coll ${ }_{\text {adsorp, }}$, amount of adsorbed collagen; $\mathrm{E}_{0, \mathrm{~s}}$, initial ground surface energy determined by chemical interactions but not nanoroughness; $\mathrm{E}_{\mathrm{s}}$, surface energy; $\mathrm{FN}_{\text {adsorp }}$, amount of adsorbed fibronectin; $\mathrm{RMS}_{\text {eff }}$ effective root mean squared roughness.

is Coll adsorp $=-0.03 \times \mathrm{E}_{\mathrm{s}}+1.87\left(R^{2}=0.26\right)$, and for fibronectin adsorption it is $\mathrm{FN}_{\text {adsorp }}=-0.03 \times \mathrm{E}_{\mathrm{s}}+1.71\left(R^{2}=0.36\right)$. Table 2 summarizes the coupling constants obtained by linear fitting the experimental results to the proposed protein adsorption model. As can be seen, the aforementioned equations that were developed by Khang et $\mathrm{al}^{16}$ did not correlate well with the data from the present experiment, although the general trend of greater protein adsorption with surface roughness held true.

\section{Discussion}

In this study we synthesized a model PLGA surface with varied nanofeature surface topographies, while keeping the 
Table 2 Parameters obtained by line fitting the experimental values with the proposed protein adsorption model

\begin{tabular}{ll}
\hline Line fitting parameters & Value \\
\hline $\mathrm{E}_{0, s}$ & 8.92 \\
$\rho$ & -0.47 \\
$\mathrm{~A}_{\text {collagen }}$ & 0.02 \\
$\beta_{\text {collagen }}$ & 0.17 \\
$\alpha_{\text {collagen }}$ & 0.1 \\
$A_{\text {fibronectin }}$ & 0.01 \\
$\beta_{\text {fibronectin }}$ & 0.165 \\
$\alpha_{\text {fibronectin }}$ & 0.088 \\
$\kappa_{\text {collagen }}$ & -0.213 \\
$\kappa_{\text {fibronectin }}$ & -0.186 \\
\hline
\end{tabular}

chemistry of the surfaces the same. Our results are in accord with many previously published results that as the surface nanoroughness of PLGA is increased, fibronectin and collagen adsorption increases. ${ }^{16,13} \mathrm{~A}$ linear regression model developed by Khang et $\mathrm{l}^{16}$ was tested to correlate protein adsorption with surface nanoroughness $\left(\mathrm{RMS}_{\text {eff }}\right)$ and surface energy. Importantly, the proposed model could predict the adsorption of collagen type IV and fibronectin in terms of only surface nanoroughness.

Having said that, the $R^{2}$ values for the linear regression developed by Khang et al ${ }^{16}$ did not indicate a strong correlation. We did attempt other curve fit parameters (such as a quadratic polynomial fit); however, it was not mathematically possible to calculate the individual contribution of surface roughness $(\alpha)$ and surface energy $(\beta)$ on protein adsorption. One of the possible reasons for this behavior could be the lack of enough data points to fit a curve. Alternative reasons for this behavior could be the fact that the proposed model does not take into account some of the important surface properties for the characterized PLGA materials (ie, surface charge and combined micron and nanosized surface topography). In the future, the proposed model will be revised, perhaps using a more generalized curve fitting approach, to take into account the effect of nanorough (but micron smooth) surfaces, as well as micron rough (but nanosmooth) surfaces on the adsorption of proteins. Alternatively, it is possible to add another parameter to model the surface charge on protein adsorption, where the control experiments can be completed using proteins with a net positive (lysozyme) and negative (albumin) charge (at a $\mathrm{pH}$ of 7.4). ${ }^{17,18}$ Most importantly, to increase applicability to medical devices, the model should be modified for the exposure of the arginine-glycine-aspartic acid peptide sequence containing proteins (ie, fibronectin, vitronectin, laminin, and collagen type I) to better assess the accuracy of the proposed equations to model cell attachment.

\section{Conclusion}

In this research, the effect of a nanophase topography and corresponding surface energy on fibronectin and collagen type IV adsorption was investigated using a model PLGA surface. A linear regression model developed by Khang et a ${ }^{16}$ was used to correlate surface topography and wettability with protein adsorption. Although general trends of greater protein adsorption correlated to greater nanoscale roughness, correlation coefficients when fitting the Khang et al ${ }^{16}$ equation were not strong. It is imperative to better understand the influence of each biomaterial surface property on select protein adsorption, where protein adsorption controls cellular adhesion and long-term cellular functions. The proposed linear regression-based protein adsorption model is one of the first steps to deriving a universal equation to fulfill this aim.

\section{Acknowledgment}

The authors would like to thank Northeastern University, Boston, MA, USA, for funding this research.

\section{Disclosure}

The authors report no conflicts of interest in this work.

\section{References}

1. Sharpe JR, Sammons RL, Marquis PM. Effect of $\mathrm{pH}$ on protein adsorption to hydroxyapatite and tricalcium phosphate ceramics. Biomaterials. 1997;18(6):471-476.

2. Kiu H, Webster TJ. Nanomedicine for implants: a review of studies and necessary experimental tools. Biomaterials. 2007;28(2):354-369.

3. Balasundaram G, Webster TJ. A perspective on nanophase materials for orthopedic implant applications. J Mater Chem. 2006;16(38): 3737-3745.

4. Scopelliti PE, Borgonovo A, Indrieri M, et al. The effect of surface nanometre-scale morphology on protein adsorption. PLoS One. 2010;5(7):1-9.

5. Singh AV, Vyas V, Patil R, et al. Quantitative characterization of the influence of the nanoscale morphology of nanostructured surfaces on bacterial adhesion and biofilm formation. PLoS One. 2011;6(9): $1-12$.

6. Wang $\mathrm{K}$, Zhou C, Hong $\mathrm{Y}$, Zhang X. A review of protein adsorption on bioceramics. Interface Focus. 2012;2(3):259-277.

7. Sofos F, Karakasidis TE, Liakopoulos A. Surface wettability effects on flow in rough wall nanochannels. Microfluid Nanofluid. 2012;12(1-4): 25-31.

8. Park GE, Webster TJ. A Review of nanotechnology for the development of better orthopedic implants. J Biomed Nanotechnol. 2005;1(1): $18-29$.

9. Zhang L, Webster TJ. Nanotechnology and nanomaterials: promises for improved tissue regeneration. Nano Today. 2009;4(1): $66-80$.

10. Yao C, Webster TJ. Anodization: a promising nano-modification technique of titanium implants for orthopedic applications. $J$ Nanosci Nanotechno. 2006;6(9-10):2682-2692.

11. Meirelles L, Albrektsson T, Kjellin P, et al. Bone reaction to nano hydroxyapatite modified titanium implants placed in a gap-healing model. J Biomed Mater Res A. 2008;87A(3):624-631. 
12. Webster TJ, Schadler LS, Siegel RW, Bizios R. Mechanisms of enhanced osteoblast adhesion on nanophase alumina involve vitronectin. Tissue Eng. 2001;7(3):291-301.

13. Miller DC, Haberstroh KM, Webster TJ. Mechanism(s) of increased vascular cell adhesion on nanostructured poly(lactic-co-glycolic acid) films. J Biomed Mater Res A. 2005;73(4):476-484.

14. Carpenter J, Khang D, Webster TJ. Nanometer polymer surface features: the influence on surface energy, protein adsorption and endothelial cell adhesion. Nanotechnology. 2008;19(50):505103.

15. Miller DC, Haberstroh KM, Webster TJ. PLGA nanometer surface features manipulate fibronectin interactions for improved vascular cell adhesion. J Biomed Mater Res A. 2007;81(3):678-684.
16. Khang D, Kim SY, Liu-Snyder P, Palmore GT, Durbin SM, Webster TJ. Enhanced fibronectin adsorption on carbon nanotube/poly(carbonate) urethane: independent role of surface nano-roughness and associated surface energy. Biomaterials. 2007;28(32):4756-4768.

17. Garcovich M, Zocco MA, Gasbarrini A. Clinical use of albumin in hepatology. Blood Transfus. 2009;7(4):268-277.

18. Liu G, Amro NA. Positioning protein molecules on surfaces: a nanoengineering approach to supramolecular chemistry. Proc Natl Acad Sci U S A. 2002;99(8):5165-5170.
International Journal of Nanomedicine

\section{Publish your work in this journal}

The International Journal of Nanomedicine is an international, peerreviewed journal focusing on the application of nanotechnology in diagnostics, therapeutics, and drug delivery systems throughout the biomedical field. This journal is indexed on PubMed Central, MedLine, CAS, SciSearch $®$, Current Contents ${ } /$ Clinical Medicine,

\section{Dovepress}

Journal Citation Reports/Science Edition, EMBase, Scopus and the Elsevier Bibliographic databases. The manuscript management system is completely online and includes a very quick and fair peer-review system, which is all easy to use. Visit http://www.dovepress.com/ testimonials.php to read real quotes from published authors.

Submit your manuscript here: http://www.dovepress.com/international-journal-of-nanomedicine-journal 